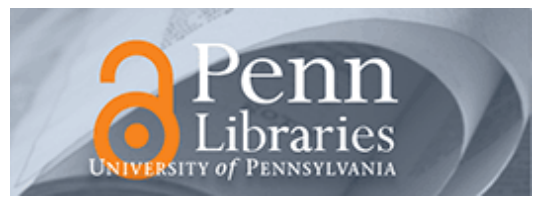

University of Pennsylvania ScholarlyCommons

July 2008

\title{
Improving the Persistence of First-Year Undergraduate Women in Computer Science
}

Rita M. Powell

University of Pennsylvania, rpowell@seas.upenn.edu

Follow this and additional works at: https://repository.upenn.edu/seas_docs

Powell, Rita M., "Improving the Persistence of First-Year Undergraduate Women in Computer Science" (2008). Engineering Documents. 3.

https://repository.upenn.edu/seas_docs/3

Postprint version. Copyright ACM, 2008. This is the author's version of the work. It is posted here by permission of ACM for your personal use. Not for redistribution. The definitive version was published in Proceedings of the 39th SIGCSE Technical Symposium on Computer Science, pages 518-22.

Publisher URL: http://doi.acm.org/10.1145/1352135.1352308

This paper is posted at ScholarlyCommons. https://repository.upenn.edu/seas_docs/3

For more information, please contact repository@pobox.upenn.edu. 


\title{
Improving the Persistence of First-Year Undergraduate Women in Computer Science
}

\author{
Abstract \\ This paper describes a study of undergraduate women's retention in the first-year of the computer science \\ major at the University of Pennsylvania for the purpose of identifying the underlying issues responsible \\ for attrition. The subsequent steps taken by the faculty to improve women's retention is also discussed.

\section{Keywords} \\ attrition, curriculum, gender issues, persistence, computer science education

\section{Comments} \\ Postprint version. Copyright ACM, 2008. This is the author's version of the work. It is posted here by \\ permission of ACM for your personal use. Not for redistribution. The definitive version was published in \\ Proceedings of the 39th SIGCSE Technical Symposium on Computer Science, pages 518-22. \\ Publisher URL: http://doi.acm.org/10.1145/1352135.1352308
}




\title{
IMPROVING THE PERSISTENCE OF FIRST-YEAR UNDERGRADUATE WOMEN IN COMPUTER SCIENCE
}

\author{
Rita Manco Powell \\ University of Pennsylvania \\ 3330 Walnut Street \\ Philadelphia, PA 19104 \\ 215-898-0051 \\ rpowell@cis.upenn.edu
}

\begin{abstract}
This paper describes a study of undergraduate women's retention in the first-year of the computer science major at the University of Pennsylvania for the purpose of identifying the underlying issues responsible for attrition. The subsequent steps taken by the faculty to improve women's retention is also discussed.
\end{abstract}

\section{Categories and Subject Descriptors Gender}

\section{General Terms \\ Diversity, Curriculum Issues}

\section{Keywords}

Gender Issues, Persistence, Attrition, Curriculum

\section{Introduction}

Enrollment in computer science programs nationally began to decline after the technology bust at the turn of the millennium, but the sharpness of the decline in women has been more pronounced. All science and engineering majors have experienced a steady increase in women's participation over the past two decades except for computer science. The goal of a study in the 2003-04 academic year was to find out why this situation was occurring at the University of Pennsylvania and determine how Penn's Department of Computer and Information Science could better support women's persistence.

\section{Background}

Applicants to the University of Pennsylvania apply to one of the university's four undergraduate schools and matriculate in that school in the freshman year. Students may transfer out of a department and/or a school at the end of the freshman year. Most undergraduate attrition from the computer science majors for both women and men at Penn occurs in the first year of college. Women comprise approximately 20 percent of the CIS incoming class of declared majors each year. While more male students join the department after the freshman year than transfer out, the proportion of women in a class decreases. The goal of this study was to understand the nature of these women's experiences in the major, how the students' interpreted these experiences, and the impact they had on students' decision to remain in or drop out of the major.

\section{Review of the Literature}

Many women enter computer science programs with far less experience with computers than men. From 19962004 , girls made up only $16-17$ percent of those taking the AP Computer Science A exam and approximately 10 percent of those taking AP Computer Science $A B$ exam [3], suggesting girl's lack of preparation in high school to study computer science in competitive academic programs in college. The home environment highly influences a woman to develop an interest in computer science. In their study at Carnegie Mellon University, Margolis and Fisher [10] found that 40 percent of the men and 65 percent of the women came from households in which one or both parents were involved in computing. In addition, 75 percent of the men in their study fit the profile of someone who was magnetically attracted to computers since childhood, while only 25 percent of the women fit this profile. Although men as well as women are drawn to computer science for the challenge and the opportunities afforded by the discipline to solve problems and advance the body of knowledge in diverse fields, the mythology of the computing "geek" who has an inordinate 24/7 fascination with the computer pervades current interpretations of who does computer science. However Blum and Friege [2] found that after the freshman year, male and female students who persisted in computer 
science claimed to fit in well with the computing culture both academically and socially.

In college, aspects of the classroom and lab environment can deter women's persistence. Being subjected to a locker-room environment, enduring inappropriate language and continuous rude and patronizing behavior, and feeling like they constantly must prove themselves and their right to be there isolates women in computer science, forming the basis for the chilly climate hypothesis in the discipline [1], [8], [9], [13]. Although Strenta et al [14] found no evidence for a chilly climate hypothesis in science, math and engineering majors because for those whose grades were the same, persistence was the same, their research did detect a significant gender effect in women's persistence in computer science. Increasing the critical mass of women was found to increase women's persistence in the computer science major [5], [10], [11].There is little evidence that negative experiences with faculty are a factor in women's attrition in computer science. Rather it is more what faculty fails to do in terms of mentoring that cause women to consider leaving science, math and engineering majors. The presence of female faculty is critically important to making the participation of women in a discipline appear and feel normal. However, the presence of a lone female advisor, which is often the case, will not be enough to address the difficulties women students experience because of their minority status [4], [6], [12]. Women Teaching Assistants and upperclass students can nurture undergraduate students, serve as role models and mentors, and help undergraduates to stay grounded and focused in the major.

\section{The Situation at Penn}

In the 2003-04 academic year, all first-year computer science students enrolled in a two semester course sequence CSE 120 and 121, Introduction to Programming and Techniques I and II and the labs associated with these courses, CSE 130 and 131. Enrollment and graduation records show that CIS graduates close to the same number of students that the department admits. The transfer-in of students into the department masks the attrition out of the department. In the academic year prior to this research study, 5 of 11 students or 45 percent that switched out of CIS from November 2002 through May 2003 were women. Conversely, only 1 of the 14 students or 7 percent who transferred into CIS during this same time period was a woman. Women made up 25 percent of the introductory computer science course CSE 120 enrollment in fall 2002. By January 2003, women comprised only 19 percent of CSE 121, the second course of the first year sequence.

\section{Research Methodology}

All twenty four women enrolled in CSE 120 in the fall of 2003 were invited to be a part of this study. Fourteen students agreed to participate; all of these students reported that they planned to major in computer science or were seriously considering the major. The research method employed in this study included a series of indepth, semi-structured personal interviews beginning in fall 2003 and continuing through the following fall. Other data sources included two focus groups with the study participants, a focus group with nine male students in the first-year courses, and a focus group with the combined female study group and male first-year focus group. The study participants were also asked to keep journals to record their experiences in computer science. In addition, personal interviews with faculty and administrators, teaching assistants, and female graduate students at the University of Pennsylvania informed this study. The names of all of the students in this study have been changed to maintain their anonymity.

The small sample size of this population made it difficult to derive meaningful results from statistical research methods. An ethnographic, qualitative approach was taken to examine the unique experiences of each individual in the study group and determine what support the department could provide to positively impact her persistence in the major. While this research approach cannot draw conclusions that may be generalized to women in other schools, it provided reliable data on the study participants' personal experiences and a context within which their decisions to persist with or leave the computer science major at the University of Pennsylvania could be examined. Therefore, this study may serve as a useful comparison to other schools and departments of computer science grappling with the issues surrounding their own female students' persistence.

\section{Issues Impacting Persistence: The Students' Accounts}

More than half of the study participants' fathers and several of their mothers were computer scientists or engineers, suggesting the importance of early modeling and encouragement of technology careers for girls. The participants described how their families and middle and high school teachers had nurtured their aptitude for mathematics, and excelling in mathematics in high school was a major contributory factor in their decision to study computer science at Penn. Although the study participants' pre-college background included a thorough grounding in math and science, most participants reported an inadequate exposure to computer science in high school. As mentioned earlier, although no previous experience with computing was required in the first course in the major, many of the male students in the class actually had a great deal of prior experience from high school, while other male students claimed to have this prior experience. Both academically and psychologically, the disparity in prior experience with computing in the first-year class worked against the study participants' motivation in that they found it very difficult to keep up with many of their classmates. They perceived that the introductory course did not afford them a level playing field on which 
to compete. One student described how this situation

had impacted her:

I remember, for the weekly homework problems we had to do in CSE 120, it was often very mindboggling and frustrating because I felt like I should somehow be explaining on my own [sic] to acquire some of the advanced knowledge of programming techniques some people in the class already had. My friends and I would spend hours and hours doing a problem only to find out, after submitting the problem, that someone had spent merely 30 minutes on the same problem not because he was a genius or particularly smart (I define being smart as being able to go further and faster than anybody with whom you have started out on the same foot) but because he, with his 3-4 years of experience, already knew some tricks on the lessons that were to be covered later in the course. There really is nothing more frustrating than this, because you never know what you don't know. Maybe it's because it was an introductory class, and thus everybody was at different levels, but still, you really begin to develop learned-helplessness and just sort of give up.

(E. Choi, personal communication, January 18, 2004)

Although a few of the women were exposed to computer programming in high school through the AP A computer science course, only one of them took the $A P A B$ advanced course. Several of the students reported that prior to college they did not participate in computing courses and robotics clubs because they did not have enough experience in high school to compete with males. Most of the women struggled in the first-year of their computer science courses to maintain the confidence that they could be successful and consequently to maintain their interest in the major and their belief that it was a good fit for them.

In addition to a lack of prior experience with programming, social isolation from faculty and peers in the computer science major made the first year difficult for many of the women. Social isolation was partially the result of the students' gender minority status in that they became acquainted with few of their classmates, and they were not included in many of their male classmates' discussions and activities. Several were too timid to insert themselves into social situations with their classmates, and the first-year courses did not facilitate enough interaction among students. One student described the effect of being excluded from group discussion in lab had on her:

Today, almost two months into the school year, we had our first "group" project in CSE 130 lab ... While a few of the guys knew each other from outside sources and began to chat easily over topics of mutual interest, I found conversation difficult to begin. Once past asking them their name, which a few timidly answered and none ever asked mine though I am sure not one knew it, I found they would all turn back to one of the other guys to continue chatting. It's odd because even one of the guys that I initially had befriended at the beginning of the year [acted this way].

(G. Pie, personal communication, October, 2003)

The social isolation, which most of the women in the study group experienced, was exacerbated by faculty's insistence that students work alone on homework programming assignments in the first-year courses, referring questions only to their instructor or course TA. Working with another student often constituted cheating by the faculty, even though many of the students were struggling with the same material. This restriction marginalized many of the women in the sample by limiting their opportunities to become a part of the informal social peer network where college has a major impact on students. This approach to programming also gave students the mistaken impression that software engineers work alone in an isolated environment, whereas almost all software projects in industry require teamwork and collaboration.

Just as these women passed most of the first-year knowing few of their classmates, they also made few personal acquaintances with faculty. They did not seek out professors during their office hours because they feared that they did not have a suitable question to ask the professor, and that he would question what prompted them to come to his office hours. Because they lacked the courage to approach faculty, most of the students relied on Teaching Assistants (TAs) to answer their questions concerning course material and assignments. The women were scattered throughout seven CSE 130 lab recitation sections, precluding a critical mass of women in any one lab section, and most became acquainted with few other women in the class during the first semester. Although the students enjoyed their residential experience at Penn, they encountered few computer science majors and no other female majors in their college houses. The residential experience helped them bind with the broader university, but did not especially support their affiliation with the School of Engineering and Applied Science or the Department of Computer and Information Science. Therefore, most of these women passed the first semester and a good part of the second semester making few, if any, friendships or contacts in engineering or computer science.

The participants initially did not value all-women support groups in the freshman year. Several women reported that they shunned women's groups and activities designed to support them because they believed that their participation in such a group was a tacit admission that they were less capable than the men. In a focus group, one student explained:

There is no guys' group. Why is there a girls' group? I see us just as individuals, not as girls and guys. We are all the same. If you think women need a support group, it's like women need help, they are weaker. 
Although these students were put off by offers early in the freshman year to join an all women's mentoring group, their attitudes noticeably changed as the freshman year progressed. By the end of the first-year, several students expressed appreciation for all-women's support groups in computer science because they provided them with opportunities to discuss academic and social issues concerning the major.

While many women and men differ in their secondary school background in computer science, they may also differ in their motivations to study computer science in college. Some students become engaged in computer science initially through their fascination with the actual operating of the computer, while others are more often attracted to the applications of computer science to diverse fields such as graphics, artificial intelligence, cognitive science, and biocomputing [11], [1], [5]. Since many women lack pre-college experience with computing, their lack of knowledge about the field could explain why women tend to look for tangible applications for computer science. In the fall focus group, one woman described her view of the differences in the appeal of the discipline for her as compared to some of her male classmates.

It's not just that the guys have taken classes before. I know guys who have Linux on their computers because they figured out how to use it. They didn't take a class on it or anything, but they play with it constantly. They like that sort of thing. The easiest way to learn CS is to actually do it. You start to think you are not the type because you are not playing with Linux constantly. I'm not particularly interested in playing with it all the time. I like to be able to use it.

(L. Hermine, personal communication, October 2003)

Although all of the women in this study believed that a computer science degree would garner them a good job after graduation, most could not visualize or describe what that job would be like. This lack of knowledge of the computing field became a significant deterrent to persistence for these women because their first college experience with computing was limited to programming, and they developed the perception of the discipline as a solitary activity of writing and debugging code. Several women worried that they did not feel passionate about computer science and were not as "gung ho" about computer programming as their peers. Those who did not enjoy programming assumed that computer science must not be for them, and yet they had little else to look to for a possible fit for their interests in the major.

\section{Academic Results of the Study Group}

Thirteen of the fourteen study group participants completed CSE 120. The only student who did not complete the class dropped after the first midterm in which she had earned a B. Nine of the fourteen women persisted in the major, enrolling in CSE 121/131 in January '04, and all nine continued in the major in the following fall. As a group, the study participants completed CSE 120 one point below the class mean grade and completed CSE 121 one point above the class mean.

\section{Impacting Persistence: The Department's Response}

The first-year experience in computer science at Penn has significantly changed since 2003 . Through curriculum, policies and practices, computer science departments can mitigate gendered attrition rates [4]. The department chair's teaching CSE 120 has sent a strong message of the importance of students' early experiences in the major. The faculty has created multiple pathways into Penn's computer science majors. Now only students with substantial prior experience with computer programming from high school and who pass a course waiver test are recommended to begin the major with CSE 120. Students with little previous experience with computer programming who express an interest in the computer science major enroll in CSE 110 Introduction to Computer Programming, a less intensive, slower paced course, which gives students time to develop the skills and confidence to be successful in CSE 120. Faculty also revamped second and third year core courses to address computing skills that were not previously covered in the curriculum, thereby ensuring that all students had the requisite skills to be successful as they moved through the core sequence.

In addition to reworking the curriculum, the culture of the CIS department has changed. More opportunities within the department to interact with computer science faculty play to students' interests in the applications of computer science. One lab period is now set aside to give first-year students the opportunity to chat with faculty in small groups about research and careers. Faculty reach out to students through office hours, which are now informal meetings and therefore less intimidating and regularly attended by more students. The summer research program for undergraduates has been expanded and faculty encourage students to engage in research projects in the summer after the freshman year. Freshmen are assigned a core group of faculty advisors with whom they meet for orientation and lunch on the first day of the fall semester. The advisors also engage new students individually and in small groups for informal advising coffees early in the semester to become better acquainted with their new students. Advising pizza parties to assist students in selecting courses for the next semester have become popular department events, well-attended by both students and faculty. Gatherings such as these held for freshmen throughout the year serve to establish a community for new students, integrating them early into the life of the department. Building personal relationships with faculty encourage students to become more engaged with the subject matter and to persist with the major.

First-year students gain the advantage of peer 
support through joining a Penn Mentoring group which meets weekly throughout the academic year under the leadership of upper-class computer science students. The mentors leading the all-women's group realized that many of the women studying computer science might be grappling with the same issues that faced those in their group and in 2003 they organized the Women in Computer Science (WICS). Events hosted by WICS provide students with opportunities to discuss curriculum with faculty, meet with recruiters from sought after companies to prepare for internship and job interviews, and make friendships with other students in the major. Other areas on which the computer science department has focused include first-year students' interactions with TAs, active learning techniques in TAdirected labs, and students' ability to access academic mentoring and tutoring support. Instructional staff carefully selects, trains and monitors TAs, and introduced paired programming activities and team assignments as a part of weekly lab recitations. The changes in the computer science curriculum, along with a more highly developed community affording frequent faculty/student and peer interaction in the computer science department at Penn is credited with improving the persistence of first-year women undergraduates from $50 \%$ in 2003 to $85 \%$ in 2005 , where it has remained, a rate equal to male persistence in the major.

\section{Conclusion}

This research study found that many of the study participants began the computer science major with an inadequate background from high school in the subject, causing them to struggle to perform as well as their peers with more computer science experience. Because of this fact, which was further heightened by the women's perception that the male students knew more than they, several women lost confidence in their ability to be successful in the major and subsequently lost interest in the major. Social isolation accompanied their gender minority status within their peer group further weakening their resolve to persist. However, this research also suggests that creating more entry points into the major which allow students to begin their studies with others at the same level, and creating more opportunities for a community to develop which is characterized by more frequent interaction for students with faculty and peers, could support the retention of women in the first year of the major. This study also suggests that the issues that undermine women's persistence may also be undermining that of some male students and they may benefit from the same initiative designed to support women.

While only 50 percent of first-year women persisted in computer science at Penn in 2003, 85 percent of the women stayed in computer science in 2005 and in the subsequent years, a proportion equal to the persistence of first-year male students at Penn. The sum of the effects of these academic and community building activities serves to integrate new students early into the fabric of department life and to foster confidence early on in their computing ability. The current retention data at the University of Pennsylvania suggests that this approach produces a more satisfied, productive student.

\section{References}

[1] American Association of University Women. (2000). Tech Savvy: Educating Girls in the New Computer Age. American Association of University Women Educational Foundation: Washington D.C.

[2] Blum, L and C. Friege. (2005). In a More Balanced Computer Science Environment, Similarity is the Difference and Computer Science is the Winner. Computing Research News. 17 (3).

[3] College Board Summary Reporting Service (College Board). College Bound Seniors: A Profile of SAT Program Test Takers. Covering the years from 1996-2006. New York: College Board. Retrieved on February 25, 2007.

[4] Cohoon, J. McGrath. (1999). Departmental Differences Can Point the Way to Improving Female Retention in Computer Science. SIGCSE Bulletin 31 (1), (pp. 198-202).

[5] Cohoon, J. McGrath. (2001). Toward Improving Female Retention in Computer Science. Communications of the ACM. 44 (5), (pp.108-114).

[6] Etzkowitz, H. (1994). Who Will Do Science? In Educating the Next Generation. W. Pearson and I. Fechter, (Eds.) Baltimore: John Hopkins University Press.

[7] Etzkowitz, H., Kemelgor, C. and Uzzi, B. (2000). Athena Unbound: The Advancement of Women in Science and Technology. London: Cambridge University Press[

[8] A. Pearl, M. E. Pollack, E. Riskin, B. Thomas, E. Wolf and A. Wu, Becoming a Computer Scientist: Report of the Committee on the Status of Women in Computer Science, Communications of the Association for Computing Machinery, 33(11):4857, 1990.

[9] Gurer, D., and T. Camp. (2001). Investigating the Incredible Shrinking Pipeline for Women in Computer Science. (Final Report-NSF Project 9812016).

[10] Margolis, J. \& Fisher, A. (2002). Unlocking the Clubhouse: Women in Computing. Cambridge, MA: The MIT Press.

[11] MIT EECS Committee on Women Undergraduate Enrollment. (1995). Women Undergraduate Enrollment in Electrical Engineering and Computer Science at MIT. Cambridge, MA: Massachusetts Institute of Technology.http://wwweecs.mit.edu/AY9495/announcements/13.html.

[12] Seymour, E., \& Hewitt, N. (1997). Talking About Leaving: Why Undergraduates Leave the Sciences. Boulder, Colorado: Westview Press.

[13] Spertus, E. (1991). Why are There So Few Female Computer Scientists? (Al Technical Report 1315). Cambridge, MA:, MIT, Artificial Intelligence Lab.

[14] Strenta, A., et al. (1994). Choosing and Leaving Science in Highly Selective Institutions. Research in Higher Education. 35 (5), 13-547. 